\title{
Sonographic Risk Assessment for An Unplanned Operative Delivery: A Prospective Study
}

Sharon Perlman ( $\nabla$ drsharonperlman@gmail.com )

Rabin Medical Center https://orcid.org/0000-0002-8023-0679

\section{Hanoch Schreiber}

Rabin Medical Center

\section{Zvi Kivilevitch}

The Chaim Sheba Medical Center

\section{Ron Bardin}

Rabin Medical Center https://orcid.org/0000-0003-4545-7234

\section{Eran Kassif}

Tel-Aviv University

\section{Reuven Achiron}

Tel-Aviv University

\section{Yinon Gilboa}

Rabin Medical Center

\section{Research Article}

Keywords: Angle of progression, pubic arch angle, unplanned operative delivery.

Posted Date: June 14th, 2021

DOl: https://doi.org/10.21203/rs.3.rs-522672/v1

License: (c) (i) This work is licensed under a Creative Commons Attribution 4.0 International License.

Read Full License

Version of Record: A version of this preprint was published at Archives of Gynecology and Obstetrics on February 2nd, 2022. See the published version at https://doi.org/10.1007/s00404-022-06413-7. 


\section{Abstract}

Purpose: To assess the value of pre-labor maternal and fetal sonographic variables to predict an unplanned operative delivery.

Methods: In this prospective study, nulliparous women were recruited at 37.0-42.0 weeks of gestation. Sonographic measurements included estimated fetal weight, maternal pubic arch angle, and the angle of progression. We performed a descriptive and comparative analysis between two outcome groups: spontaneous vaginal delivery (SVD) and unplanned operative delivery (UOD) (vacuum-assisted, forcepsassisted and cesarean deliveries). Multivariate logistic regression with ROC analysis was used to create discriminatory models for UOD.

Results: Among 234 patients in the study group, 175 had a spontaneous vaginal delivery and 59 an unplanned operative delivery. Maternal height and pubic arch angle (PAA) significantly correlated with UOD.

Analysis of Maximum Likelihood Estimates revealed a multivariate model for the prediction of UOD, including the parameters of maternal age, maternal height, sonographic PAA, angle of progression (AOP), and estimated fetal weight, with an area under the curve of 0.7118 .

Conclusion: Sonographic parameters representing maternal pelvic configuration (PAA) and maternal-fetal interface (AOP) improve the prediction ability of pre-labor models for a UOD. These data may aid the obstetrician in the counseling process before delivery.

\section{Introduction}

Despite significant advances in modern medicine, prelabor prediction of an obstructed labor and unplanned operative delivery (UOD) and its consequences [1] remains an unsolved challenge. In everyday practice, the nulligravida patient is usually provided with a raw estimate regarding her chances for a spontaneous vaginal delivery rather than a personalized estimate.

According to the classical obstetrical literature, three main factors involved in labor and delivery are fetal size, the configuration of the pelvis, and effective uterine contractions. The first two parameters can be estimated and quantified before labor onset and can be used as personal predictive factors [2-8].

The continuing effort to search for objective risk assessment, parallel with the introduction of ultrasonography equipment into the delivery rooms, has led to many reports regarding the value of various sono-pelvimetric parameters in predicting dysfunctional labor and unplanned operative delivery [9-23]. The angle of progression, widely reported in the literature as a predictive measurement when obtained before the onset of labor, during the first and second stages of labor, and before assisted delivery, represents the fetal head station. The pubic arch angle (PAA), reported by our group [24-25] and 
others [26-33] to have a strong negative correlation with persistent occiput posterior and mode of delivery, represents the primary pelvimetric diameter of the pelvic outlet.

Interestingly, some of these parameters are prone to modification by other parameters, such as maternal age [4]. These modifications exemplify the complexity of the labor mechanism, which involves many confounding factors.

The current study assessed the value of maternal and fetal sonographic variables to predict an unplanned operative delivery and created a multivariable predictive model.

\section{Materials And Methods}

\section{Study design and population}

We conducted a prospective observational study. Nulliparous women carrying a singleton fetus in vertex presentation who opted for a vaginal delivery were recruited at 37.0-42.0 weeks of gestation at the postdate clinic. The sonographic measurements obtained included fetal biometry for estimated fetal weight calculation, AOP, and PAA. The patient and the attending obstetrician were blinded to the AOP and PAA measurements. Prenatal and delivery outcome parameters were obtained from the electronic medical records. We excluded from analysis cases that underwent a cesarean section during the first stage of labor or following major obstetrical events (placental abruption, cord prolapse).

The Institutional Ethics Committee approved the study, and informed consent was obtained from each participant.

\section{Sonographic measurements}

Sonographic measurements were performed by senior obstetricians (Y.G., SP) not involved in labor management. Both measurements were performed by the same operator and calculated in real-time from the $2 \mathrm{D}$ image.

Figure 1 illustrates the measurement of the AOP using the technique described by Barbera et al. [15]. With a horizontally positioned transducer, an angle is created between a line drawn through the midline of the pubic symphysis and a line running from the inferior apex of the pubic symphysis, tangential to the fetal skull. Figure 2 demonstrates the measurement of the PAA; with a transversely positioned transducer, an angle is created at the inferior borders of the pubic rami that converge at the middle of the pubic symphysis.

\section{Statistical analysis}

The data analysis for this paper was generated using SAS software version 9.4. (SAS Institute Inc., SAS Institute Inc., Cary, NC, USA). 
Descriptive and comparative pre-labor parameters were compared between two outcome groups: spontaneous vaginal deliveries and unplanned operative deliveries, including vacuum-assisted, forcepsassisted, and cesarean deliveries. Sub-analysis was performed to assess differences between vaginal assisted and cesarean deliveries.

We excluded from the analysis women who underwent a cesarean delivery following a major obstetrical event, such as placental abruption, cord prolapse, or during the first stage of labor.

Continuous variables are presented as mean \pm standard deviation (SD), and categorical variables are presented by $(\mathrm{N}, \%)$.

Logistic regression was used to calculate odds ratios (OR) in univariate and multivariable risk models for UOD.

\section{Results}

A total of 244 women were recruited for the study. Ten underwent a cesarean delivery following a major obstetrical event or during the first stage of labor, and 59 (25.2\%) had an unplanned operative delivery. In the unplanned operative delivery group, successful operative vaginal delivery occurred in 36 women (15.4\%) and cesarean delivery in $23(9.8 \%)$.

Maternal and fetal sonographic and demographic characteristics are presented in Table 1. No significant differences were seen between the SVD and the UOD group regarding maternal age, maternal BMI, fetal biometric parameters (bi-parietal diameter, head circumference, and abdominal circumference), estimated fetal weight, and neonatal birth weight $(p>0.05)$. The sonographic PAA $(p<0.01)$ and maternal height ( $p$ $<0.05)$ differed significantly between groups. The difference in the AOP between the outcome groups was borderline $(p=0.055)$. 
Table 1

Maternal-fetal sonographic and demographic parametric variables between the spontaneous vaginal delivery and the unplanned operative delivery groups.

\begin{tabular}{|c|c|c|c|c|}
\hline $\begin{array}{l}\text { Parameter } \\
\text { Mean } \pm \text { SD, Range }\end{array}$ & SVD & UOD & $\begin{array}{l}\text { OR, 95\% Confidence } \\
\text { Limits }\end{array}$ & $\begin{array}{l}\text { Pr }>\text { Chi- } \\
\text { Square }\end{array}$ \\
\hline \multicolumn{5}{|c|}{ Maternal demographic parameters } \\
\hline Age (years) & $29.8 \pm 4.6$ & $30.8 \pm 4.4$ & $1.039(0.978-1.104)$ & 0.14 \\
\hline Height (m) & $1.65 \pm 0.06$ & $1.63 \pm 0.06$ & $0.012(<0.001-0.995)$ & 0.031 \\
\hline Body mass index & $23.2 \pm 4.6$ & $23.5 \pm 5.1$ & $0.994(0.932-1.059)$ & 0.684 \\
\hline $\begin{array}{l}\text { Gestational age at delivery } \\
\text { (weeks) }\end{array}$ & $40.3 \pm 0.99$ & $40.4 \pm 0.77$ & $1.395(0.990-1.965)$ & 0.346 \\
\hline \multicolumn{5}{|c|}{ Maternal sonographic parameters } \\
\hline PAA & $\begin{array}{l}100.47 \pm \\
8.26\end{array}$ & $\begin{array}{l}96.44 \pm \\
7.69\end{array}$ & $0.954(0.923-0.987)$ & 0.001 \\
\hline AOP & $106 \pm 17.08$ & $101 \pm 15.92$ & $0.972(0.955-0.989)$ & 0.055 \\
\hline \multicolumn{5}{|l|}{ Fetal sonographic parameters } \\
\hline EFW & $\begin{array}{l}3456.2 \pm \\
380.7\end{array}$ & $\begin{array}{l}3508.6 \pm \\
413.2\end{array}$ & $1.000(1.000-1.001)$ & 0.374 \\
\hline $\mathrm{BPD}(\mathrm{mm})$ & $\begin{array}{l}93.56 \pm \\
3.69\end{array}$ & $\begin{array}{l}93.98 \pm \\
2.97\end{array}$ & $1.024(0.942-1.113)$ & 0.338 \\
\hline $\mathrm{HC}(\mathrm{mm})$ & $\begin{array}{l}335.1 \pm \\
11.1\end{array}$ & $\begin{array}{l}336.0 \pm \\
12.2\end{array}$ & $1.006(0.988-1.023)$ & 0.580 \\
\hline $\mathrm{AC}(\mathrm{mm})$ & $\begin{array}{l}341.5 \pm \\
17.5\end{array}$ & $345 \pm 19.3$ & $1.015(0.999-1.032)$ & 0.166 \\
\hline \multicolumn{5}{|l|}{ Birth outcome } \\
\hline Birth weight (g) & $\begin{array}{l}3418.6 \pm \\
386.5\end{array}$ & $\begin{array}{l}3421.5 \pm \\
444.2\end{array}$ & $1.000(0.999-1.001)$ & 0.962 \\
\hline Cord arterial $\mathrm{pH}$ & $7.27 \pm 0.08$ & $7.25 \pm 0.09$ & $1.000(0.999-1.001)$ & 0.395 \\
\hline \multicolumn{5}{|c|}{$\begin{array}{l}\text { SVD, spontaneous vaginal delivery; UOD, unplanned operative delivery; EFW, estimated fetal weight, } \\
\text { BPD, biparietal diameter; } \mathrm{HC} \text {, head circumference; } \mathrm{PAA} \text {, pubic arch angle; AOP- angle of progression } \\
\text { OR, odds ratio, Cl - confidence interval. }\end{array}$} \\
\hline
\end{tabular}

Of note, sub-analysis within the UOD group revealed a significant difference in the AOP between the vaginal delivery group (spontaneous and assisted/instrumental) $\left(105.45^{\circ} \pm 17.31^{\circ}\right)$ in comparison to the cesarean delivery group $\left(\mathrm{AOP}=99.18^{\circ} \pm 11.13^{\circ}\right)$. 
Multivariate logistic regression with ROC analysis was used to create a discriminatory model for UOD. The discriminatory ability of the model was measured by concordance, $c$, which is equivalent to the area under the receiver-operating characteristic curve.

Various models were used to analyze a combination of prenatal ultrasound variables. (Table 2, Fig. 3). The models that included pre-labor sonographic measurements performed better than models that included only clinical parameters. The best model with an area under the curve of 0.7118 included maternal age and height, sonographic PAA and AOP, and EFW.

Table 2

Analysis of Maximum Likelihood Estimates for an unplanned operative delivery

\begin{tabular}{|lllll|}
\hline Parameter & Estimate & Standard error & Wald chi-square & Pr > Chi-square \\
\hline Intercept & 11.1241 & 4.3341 & 6.5876 & 0.0103 \\
\hline Maternal Age & 0.0787 & 0.0361 & 4.7568 & 0.0292 \\
\hline Maternal height & -6.2871 & 2.6520 & 5.6200 & 0.0178 \\
\hline Pubic arch angle & -0.0338 & 0.0183 & 3.4242 & 0.0642 \\
\hline Angle of progression & -0.0302 & 0.00970 & 9.7048 & 0.0018 \\
\hline Estimated fetal weight & 0.000716 & 0.000446 & 2.5791 & 0.1083 \\
\hline
\end{tabular}

\section{Discussion}

In this prospective study, we presented a personalized risk assessment of the likelihood of a UOD in nulliparous term patients based on a combination of maternal and fetal sonographic measurements obtained before the onset of labor. According to our findings, a UOD can be mainly predicted by AOP, PAA, maternal age, maternal height, and EFW.

UOD is associated with a higher likelihood of adverse maternal and neonatal outcomes. Cesarean delivery performed during the second stage of labor is associated with a higher risk for complications, include postpartum hemorrhage, infection, and damage to the cervix. Operative vaginal deliveries are associated with a greater incidence of maternal anal sphincter injury, neonatal intracranial hemorrhage, subgaleal hematoma, and shoulder dystocia. Prelabor identification of patients at high risk for UOD is of great importance as it may assist in deciding the optimal mode of delivery for the specific patient.

It seems reasonable that in the complex labor process, which involves many confounding factors, using a combination of parameters to predict UOD would perform better than a single parameter would.

For many years, a physical examination has been the primary tool for assessing the maternal pelvis. However, clinical pelvimetry is in danger of becoming a lost art without appropriate training, and its application in the diagnosis of cases prone to protracted labor is limited [35-36]. 
Extensive research efforts have been invested in finding a non-invasive, objective, quantitative tool to predict a successful vaginal delivery. Various sono-pelvimetric parameters were reported to predict dysfunctional labor and unplanned operative delivery [12-22]. The trans-perineal sonographic measurement of the AOP, which describes the fetal head station, was proven to be a reliable parameter with high measurement reproducibility [24-30]. Among classic pelvimetric parameters, the infra-pubic angle, the primary measure of the pelvic outlet, is measured easily by ultrasound and was reported by our group and others [25-28] to be an independent risk factor for UOD.

Interestingly, according to our data, the difference in AOP was significant only when we compared the vaginal delivery (spontaneous or instrumental) and cesarean delivery groups. We did not find a difference between spontaneous vaginal delivery and any UOD (instrumental and cesarean delivery) group. These findings are consistent with findings in previous studies that a narrower AOP correlates with cesarean deliveries, while a wider AOP correlates with a spontaneous or instrumental vaginal birth [18-20].

Giuseppe et al. [34] explored the performance of a predictive model for detecting the need for UOD and reported that $\mathrm{HC}$ and pubic angle were independent risk factors for UOD, and the combination of maternal height, pubic angle, and head circumference showed the best results. Others have reported similar results regarding the effect of a large head circumference and an unplanned cesarean section [3-7].

However, in our study group, neither BPD nor head circumference negatively influenced the statistical model for predicting a UOD. According to the results reported by Mujugira et al. [4], maternal age modified the association between fetal head circumference and primary cesarean section. This association may reflect changes in pelvic cartilage, ligaments, collagen configuration, or other metabolic changes in the skeletal system secondary to aging. Indeed, in a study assessing the effect of PAA on the second stage of labor, our group [33] found an inverse relationship between PAA and maternal age.

Limitations of this study are a relatively high rate of UOD and lack of stratification of the analysis according to cervical status and Bishop score.

The study's main strengths rely on its prospective design, representing a low-risk population for obstetrical complications regarding maternal age, maternal BMI, fetal head indices, and birth weight; and in the fact that the patients and the attending obstetricians were blinded to the sonographic measurements.

\section{Conclusion}

This study presents a simple, available bedside tool that combines measurements representing the pelvic configuration and the maternal-fetal interface performed using real-time 2-D ultrasound images. This information may aid obstetricians in the decision-making and counseling process before and during delivery, especially in rural or indigent areas in which appropriately timed transfer to a district hospital may affect maternal and neonatal morbidity. This study will be followed by further research to validate the model's strength in specific obstetrical subpopulations. 


\section{Declarations}

Funding: This study was not funded.

Conflicts of interest/Competing interests: None to declare

Availability of data and material (data transparency) available upon request

Code availability: Not applicable

\section{Authors' contributions:}

S Perlman: Project development, Data collection and management, Data analysis, Manuscript writing/editing

H Schreiber: Data management, Data analysis, Manuscript writing/editing

Z Kivilevitch: Project development, Manuscript writing/editing

R Bardin: Manuscript writing and editing

E Kassif: Manuscript writing and editing

R Achiron: Project development, Manuscript writing/editing

Y Gilboa: Project development, Data collection and management, Data analysis, Manuscript writing/editing

Other (please specify briefly using 1 to 5 words)

Ethics approval (include appropriate approvals or waivers) 0828-17-RMC, 7656-10-SMC

Consent to participate: All patients provided written informed consent to participate in the study

\section{References}

1. Ferguson JE, Sistrom CL (2000) Can fetal-pelvic disproportion be predicted? Clin Obstet Gynecol 43:247-264.

2. Peleg D, Warsof S, Wolf MF, Perlitz Y, Shachar IB. (2015) Counseling for fetal macrosomia: an estimated fetal weight of 4,000 $\mathrm{g}$ is excessively low. Am J Perinatol. 32(1):71-4

3. Elvander C, Högberg U, Ekéus C. (2012) The influence of fetal head circumference on labor outcome: a population-based register study. Acta Obstet Gynecol Scand.91(4):470-5

4. Mujugira A, Osoti A, Deya R, Hawes SE, Phipps Al. (2013) Fetal head circumference, operative delivery, and fetal outcomes: a multi-ethnic population-based cohort study. BMC Pregnancy Childbirth. 13:106 
5. Lipschuetz M, Cohen SM, Ein-Mor E, Sapir H, Hochner-Celnikier D, Porat S, Amsalem H, Valsky DV, Ezra Y, Elami-Suzin M, Paltiel O, Yagel S. (2015) A large head circumference is more strongly associated with unplanned cesarean or instrumental delivery and neonatal complications than high birthweight. Am J Obstet Gynecol.213(6): 833.e1-833.e12

6. Aviram A, Yogev Y, Bardin R, Hiersch L, Wiznitzer A, Hadar E. (2016) Association between sonographic measurement of fetal head circumference and labor outcome. Int J Gynaecol Obstet. 132(1):72-6.

7. Burke N, Burke G, Breathnach F, McAuliffe F, Morrison JJ, Turner M, Dornan S, Higgins JR, Cotter A, Geary M, McParland P, Daly S, Cody F, Dicker P, Tully E, Malone FD (2017) Perinatal Ireland Research Consortium. Prediction of cesarean delivery in the term nulliparous woman: results from the prospective, multicenter Genesis study. Am J Obstet Gynecol. 216(6): 598.e1-598.e11.

8. Floberg J, Belfrage P, Ohlsen H. (1987) Influence of pelvic outlet capacity on labor: a prospective pelvimetry study of 1429 unselected primiparas. Acta Obstet Gynecol Scand 66: 127-130

9. Korhonen U, Taipale P, Heinonen S. (2014) The diagnostic accuracy of pelvic measurements: threshold values and fetal size. Arch Gynecol Obstet.290(4):643-8

10. Korhonen U, Taipale P, Heinonen S. (2015) Fetal pelvic index to predict cephalopelvic disproportion a retrospective clinical cohort study. Acta Obstet Gynecol Scand. 94(6):615-21.

11. Pattinson RC. (2000) Pelvimetry for fetal cephalic presentations at term. Cochrane Database Syst Rev. (2):CD000161. Review.

12. Sherer DM, Abulafia O. (2003) Intrapartum assessment of fetal head engagement: comparison between transvaginal digital and transabdominal ultrasound determinations. Ultrasound Obstet Gynecol 21: 430-436.

13. Dietz HP, Lanzarone V. (2005) Measuring engagement of the fetal head: validity and reproducibility of a new ultrasound technique. Ultrasound Obstet Gynecol 25: 165-168.

14. Eggebø TM, Heien C, Økland I, Gjessing LK, Romundstad P, Salvesen KA. (2008) Ultrasound assessment of fetal head-perineum distance before induction of labor. Ultrasound Obstet Gynecol 32: $199-204$.

15. Barbera AF, Pombar X, Perugino G, Lezotte DC, Hobbins JC. (2009) A new method to assess fetal head descent in labor with transperineal ultrasound. Ultrasound Obstet Gyneco/ 33: 313-319.

16. Duckelmann AM, Bamberg C, Michaelis SA, Lange J, Nonnenmacher A, Dudenhausen JW, Kalache KD. (2010) Measurement of fetal head descent using the 'angle of progression' on transperineal ultrasound imaging is reliable regardless of fetal head station or ultrasound expertise. Ultrasound Obstet Gyneco/ 35:216-222

17. Molina FS, Terra R, Carrillo MP, Puertas A Nicolaides KH. (2010) What is the most reliable ultrasound parameter for assessment of fetal head descent? Ultrasound Obstet Gynecol. 36:493-499.

18. Tutschek B, Braun T, Chantraine F, Henrich W. (2011) A study of progress of labor using intrapartum translabial ultrasound, assessing head station, direction, and angle of descent. BJOG 118: 62-69. 
19. Levy R, Zaks S, Ben-Arie A, Perlman S, Hagay Z, Vaisbuch E. (2012) Can angle of progression in pregnant women before onset of labor predict mode of delivery? Ultrasound Obstet Gynecol. 40(3):332-7.

20. Eggebø TM, Hassan WA, Salvesen KÅ, Lindtjørn E, Lees CC. (2014) Sonographic prediction of vaginal delivery in prolonged labor: a two-center study. Ultrasound Obstet Gynecol.43(2):195-201

21. Gillor M, Vaisbuch E, Zaks S, Barak O, Hagay Z, Levy R. (2017) Transperineal sonographic assessment of the angle of progression as a predictor of a successful vaginal delivery following induction of labor. Ultrasound Obstet Gynecol.49(2):240-245

22. Bamberg C, Scheuermann S, Slowinski T, Dückelmann AM, Vogt M, Nguyen-Dobinsky TN, Streitparth F, Teichgräber U, Henrich W, Dudenhausen JW, Kalache KD. (2011) Relationship between fetal head station established using an open magnetic resonance imaging scanner and the angle of progression determined by transperineal ultrasound. Ultrasound Obstet Gyneco/ 37: 712-716.

23. Arthuis CJ, Perrotin F, Patat F, Brunereau L, Simon EG. (2016) Computed tomographic study of anatomical relationship between symphysis and ischial spines to improve interpretation of intrapartum translabial ultrasound. Ultrasound Obstet Gynecol 48: 779-785.

24. Perlman S, Kivilevitch Z, Moran O, Katorza E, Kees S, Achiron R, Gilboa Y. (2017) Correlation between clinical fetal head station and sonographic angle of progression during the second stage of labor. $J$ Matern Fetal Neonatal Med. 4:1-6.

25. Gilboa Y, Kivilevitch Z, Spira M, Kedem A, Katorza E, Moran O, Achiron R. (2013) Pubic arch angle in prolonged second stage of labor: clinical significance. Ultrasound Obstet Gynecol. 41(4):442-6.

26. Choi S, Chan SS, Sahota DS, Leung TY. (2013) Measuring the angle of the subpubic arch using threedimensional transperineal ultrasound scan: intraoperator repeatability and interoperator reproducibility. Am J Perinatol. 30(3):191-6

27. Ghi T, Youssef A, Martelli F, Montaguti E, Krsmanovic J, Pacella G, Pilu G, Rizzo N, Gabrielli S. (2015) A New Method to Measure the Subpubic Arch Angle Using 3-D ultrasound. Fetal Diagn Ther.38(3):195-9

28. Aldrich SB, Shek K, Krahn U, Dietz HP. (2015) Measurement of subpubic arch angle by threedimensional transperineal ultrasound and impact on vaginal delivery, Ultrasound Obstet Gynecol. 46: 496-500.

29. Youssef A, Ghi T, Martelli F, Montaguti E, Salsi G, Bellussi F, Pilu G, Rizzo N. (2016) Subpubic Arch Angle and Mode of Delivery in Low-Risk Nulliparous Women. Fetal Diagn Ther. 40(2):150-5.

30. Ghi T, Youssef A, Martelli F, Bellussi F, Aiello E, Pilu G, Rizzo N, Frusca T, Arduini D, Rizzo G. (2016) Narrow subpubic arch angle is associated with higher risk of persistent occiput posterior position at delivery. Ultrasound Obstet Gynecol. 48(4):511-515

31. Ghi T, Dall'Asta A, Suprani A, Aiello E, Musarò A, Bosi C, Pedrazzi G, Kiener A, Arduini D, Frusca T, Rizzo G. (2017) Correlation between Subpubic Arch Angle and Mode of Delivery in Large-forGestational-Age Fetuses. Fetal Diagn Ther. [Epub ahead of print] 
32. Rizzo G, Aiello E, Bosi C, D'Antonio F, Arduini D. (2017) Fetal head circumference and subpubic angle are independent risk factors for unplanned cesarean and operative delivery. Acta Obstet Gynecol Scand. 96(8):1006-1011

33. Perlman S, Raviv-Zilka L, Levinsky D, Gidron A, Achiron R, Gilboa Y, Kivilevitch Z. (2018) The birth canal: correlation between the pubic arch angle, the interspinous diameter, and the obstetrical conjugate: a computed tomography biometric study in reproductive age women. J Matern Fetal Neonatal Med. 22:1-11.

34. RIZZO, Giuseppe, et al. (2017) Fetal head circumference and subpubic angle are independent risk factors for unplanned cesarean and operative delivery. Acta Obstetricia et Gynecologica Scandinavica.96.8: 1006-1011.

35. Rozenholc AT, Ako SN, Leke RJ, Boulvain M. (2007) The diagnostic accuracy of external pelvimetry and maternal height to predict dystocia in nulliparous women: a study in Cameroon. BJOG. 114(5):630-5.

36. Liselele HB, Tshibangu CK, Meuris S. (2000) Association between external pelvimetry and vertex delivery complications in African women. Acta Obstet Gynecol Scand. 79(8):673-8

\section{Figures}




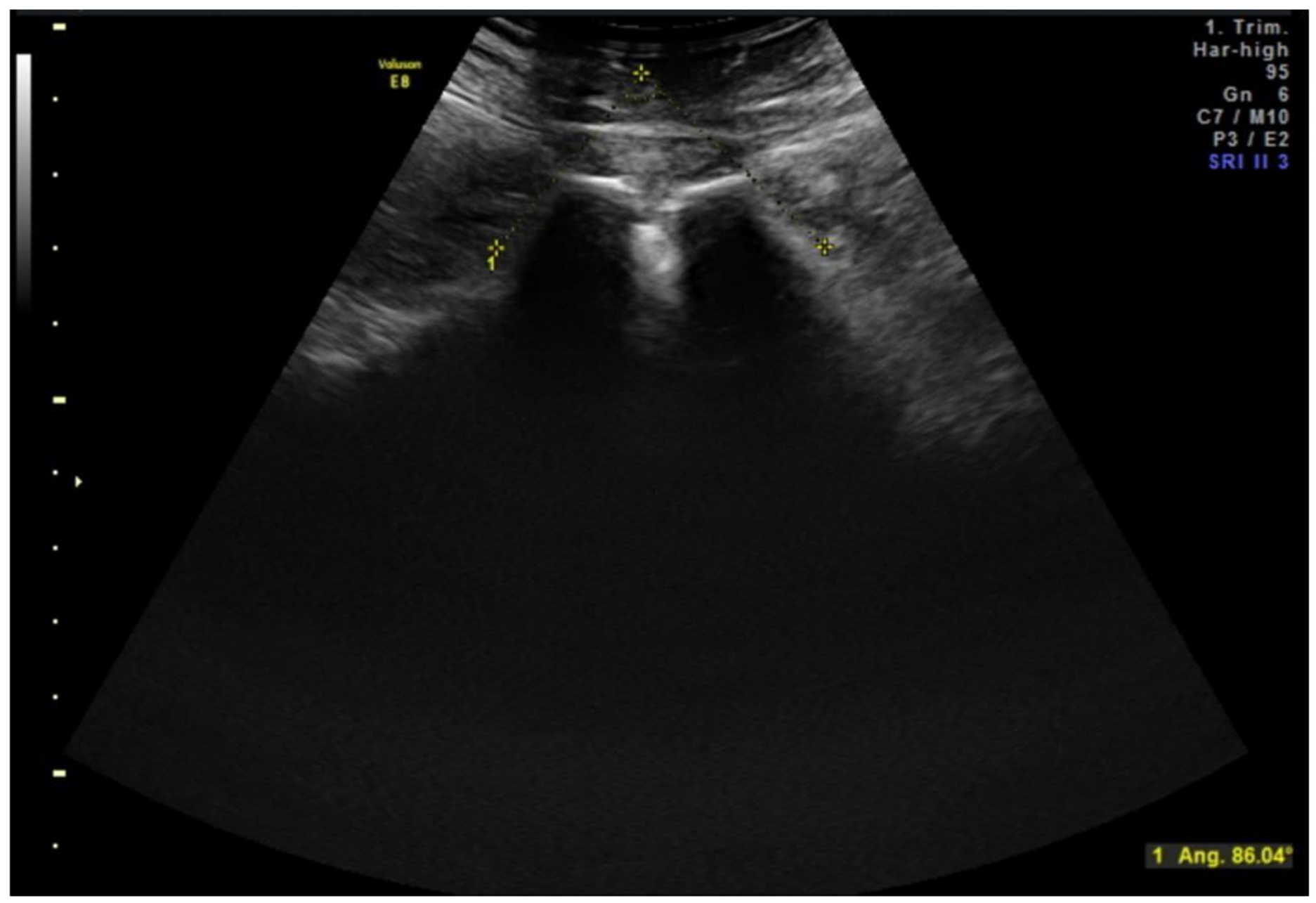

\section{Figure 1}

Transperineal ultrasound imaging and measurement of the pubic arch angle (PAA). An angle is created between lines drawn at the inferior borders of the pubic rami that converge at the middle of the pubic symphysis. 


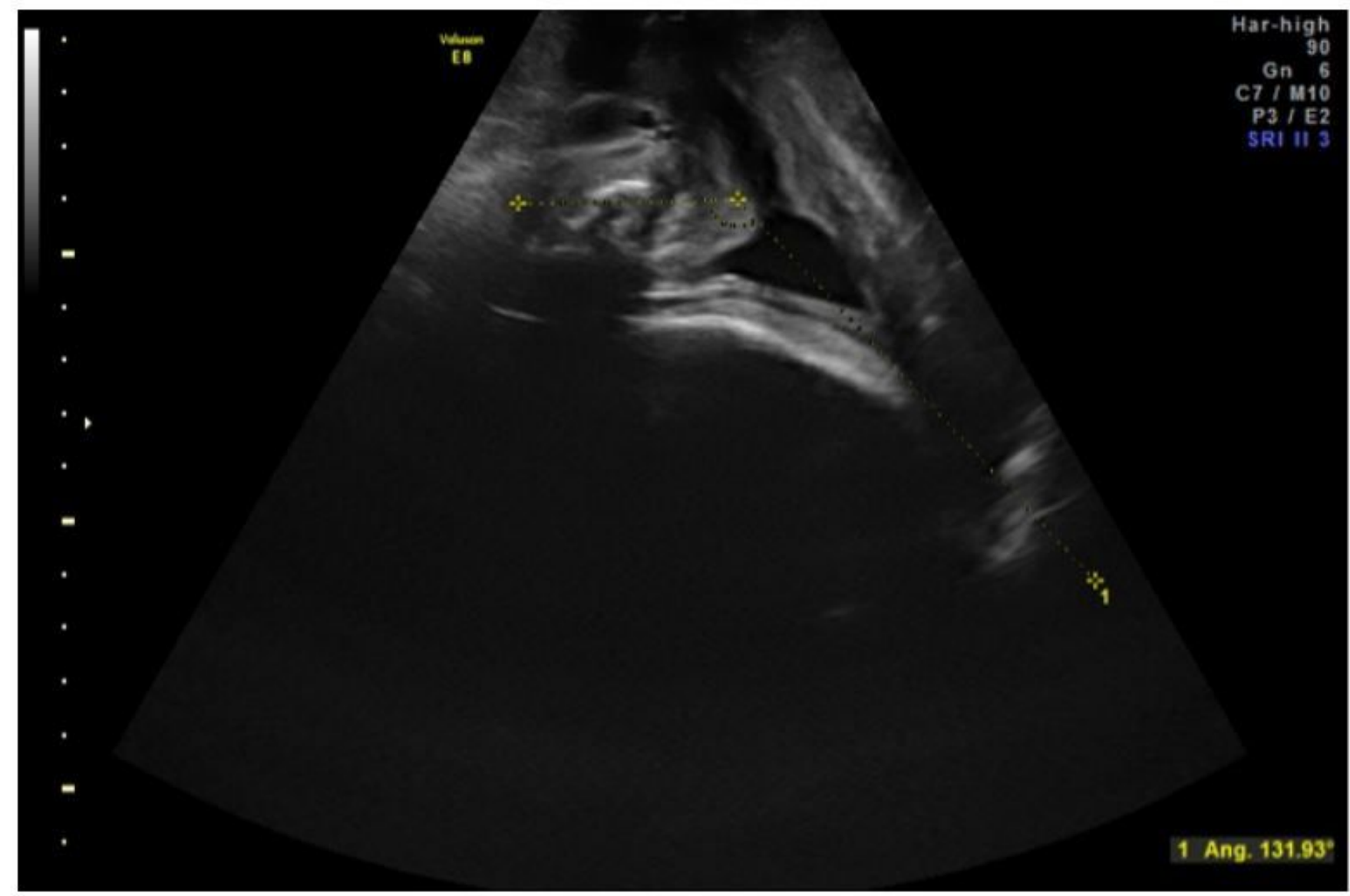

\section{Figure 2}

Transperineal ultrasound imaging and measurement of the angle of progression (AOP). An angle is created between a line drawn through the midline of the pubic symphysis and a line running from the inferior apex of the pubic symphysis, tangential to the fetal skull. 


\section{ROC Curves for All M odel Building Steps}

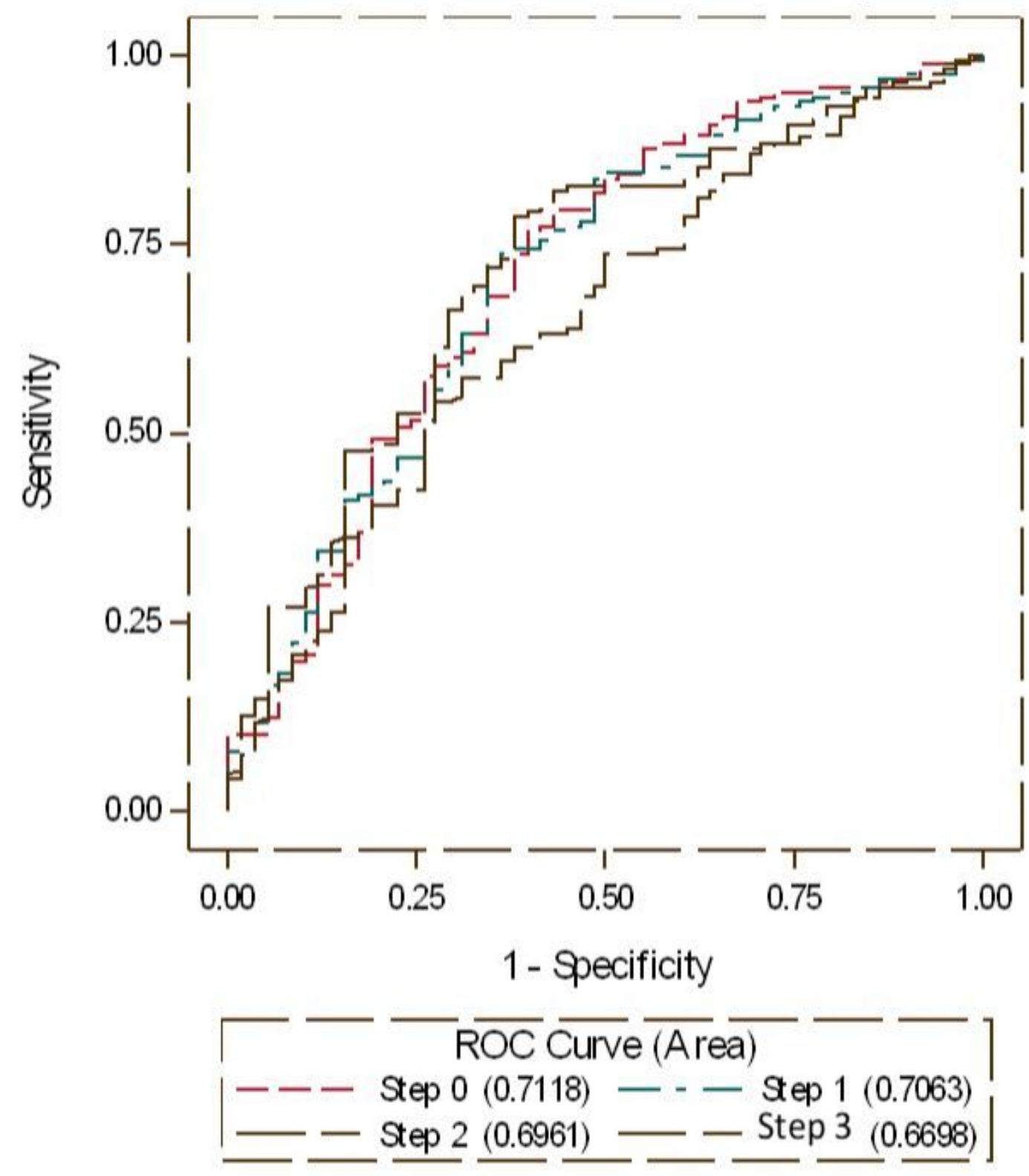

Figure 3

Receiver operating characteristic (ROC) curve of the multivariable model for predicting unplanned operative delivery Step 0: Combination of AOP, PAA, maternal age, maternal height and EFW. Step 1: Combination PAA, maternal age, maternal height and EFW. Step 2: Combination AOP, PAA, maternal height and EFW. Step 3: Combination AOP, PAA, maternal age and maternal height. AOP- angle of progression; EFW, estimated fetal weight; PAA, pubic arch angle 